\title{
12
}

\section{'This In-Between': How Families Talk about Death in Relation to Severe Brain Injury and Disorders of Consciousness}

Celia Kitzinger and Jenny Kitzinger

\section{Introduction}

It's almost like living with a dead person. Some people say, 'you've still got her'. No I haven't. (Mother of a daughter in a permanent vegetative state, caring for her at home.)

I only thought in terms of life and death ... not this, this in-between. (Father of a son, who had been in a minimal conscious state.)

And I'd thought of every single possibility. But I hadn't thought of this one. Because I didn't even know it existed. (Sister of a woman in a permanent vegetative state.)

These comments encapsulate some common themes in how people describe having a severely brain-injured relative in a coma-like condition, medically known as a 'disorder of consciousness'. In the past it was highly unusual for such individuals to survive very long after the initial trauma that caused their injury. However, the emergence of modern medical technologies, and how they are deployed, has led to the creation of new long-term conditions including the 'vegetative state' (in which the patient shows no awareness at all) and the 'minimally conscious state' (in which the the patient displays some intermittent and minimal awareness). These conditions are modern phenomena - the vegetative diagnostic category was first created in the early 1970s (Jennett and Plum, 1972) and the 'minimally conscious state' [MCS] was only defined in 2002 (Giacino et al., 2002). Patients with disorders of consciousness 
disrupt previous ways of understanding life. The family may experience their vegetative or minimally conscious relative as 'present but absent', 'living, but dead', making comments such as 'this is no life' and 'my son is gone' - and experiencing a sense of loss and grief that may be 'like a death', although not a death.

In analysing families' talk about death in relation to severe brain injury and disorders of consciousness, this chapter combines a social constructionist approach - addressing the way new medical technologies generate dominant definitions of death and dying - with a social constructivist approach - focusing on the agency of relatives in generating constructions of their relative in relation to the vegetative and minimally conscious diagnoses. We explore what family members' accounts tell us about 'ordinary understandings' of death, the disruption of such understandings brought about by the use of medical technologies which 'rescue' and sustain physiological life with no (or minimal) consciousness and the ways in which family members negotiate such disruptions.

\section{The social construction of 'the vegetative state'}

Death is sometimes seen to defy social constructionist/ivist theorising - death is the ultimate, non-negotiable, purely natural, 'fact of life' (Carpentier and Van Brussel, 2012). However, thanatologists have detailed the changing social nature of death, who 'owns' death and where it occurs (Illich, 1975; Aries, 1981) as well as highlighting how new 'life-sustaining' technologies have led to new definitions of death and how the space between life and death is historically and socially constructed and contested (Lock, 2002). 'Brain death' is one obvious, and well analysed, example but the most profound disability that can result from surviving severe brain injury but which does not (currently) result in a diagnosis of death is the 'vegetative state' (sometimes now called 'wakeful unresponsiveness' - 'wakeful' because their eyes open, even if the patient can see nothing). It is this condition and the more 'borderline' condition of 'minimally conscious state', and more specifically the construction of these conditions in terms of 'in-between' states of being, that is the focus of this chapter.

The vegetative and the minimally conscious state conditions cannot be isolated from a specific medical-material context. Increasing numbers of people are now surviving injuries caused by, for example, a car crash, sporting accident, assault, a cardiac arrest or an illness such as viral encephalitis (surviving both in the immediate aftermath and for years or decades afterwards). This is linked to late twentieth and early twenty-first 
century developments in medical technologies (including resuscitation, artificial ventilation and the delivery of artificial hydration and nutrition), which - combined with particular sets of social and political imperatives - have helped to save lives and improve recovery for some, but at the same time have 'produced new neurological syndromes of severe, and usually irreversible, cognitive and motor disabilities' (Cranford, 2002, p. 129). Indeed, Kaufman and Morgan talk of new 'technologically produced' life forms - 'liminal beings' who 'hover in an ambiguous zone' and 'force a remapping of the notions of life, death, and person', throwing up new ethical and cultural debates (Kaufman and Morgan, 2005, p. 330). There is now a large body of clinical literature debating the ethics of medical decision-making at the very borders of life (Abdennour et al., 2007; Carter and Leuthner, 2003; Gillett et al., 2010; Honeybul et al., 2011; Schaller and Kessler, 2006; Wilkinson and Savulescu, 2011). There is also an emerging literature on the sociological significance of these patients and their care (Bird-David and Israeli, 2010; Kaufman, 2003, Kaufman and Morgan, 2005; Kitzinger and Kitzinger, 2013). From this, and related work on 'brain death' (Giacomini, 1997; Lock, 2002; Kaufman and Morgan, 2005; Youngner et al., 1999), it is clear that professionals and patients' families are often troubled by the ethics of 'lifesustaining' interventions for such patients and find it hard to make sense of patients who are neither fully alive nor unambiguously dead.

Alongside new medical technologies, allowing medical staff to keep patients alive and (clinical) debates on life-sustaining interventions, arose the urge to define the condition of the vegetative state - which returns us to the constructed nature of death. From a (dominant) biological paradigm, death is defined as the irreversible breakdown in the functioning of the organism as a whole: in that paradigm brain-dead patients are dead because they have lost consciousness and are machinedependent for functions such as breathing, but the patients in permanently vegetative states [PVS] are alive because although they have lost consciousness, they maintain integrated autonomic physiological functions (albeit machine-dependent for nutrition and hydration). However, critics point out that the dominant biological paradigm fails to capture the totality and complexity of the phenomenon of 'death'.

As Holland points out:

Death is one of a handful of most weighty phenomena. It would be odd if concepts capturing such phenomena turn out to be simple and, unsurprisingly, we find that concepts such as life, love and liberty turn out to be complex, and their definitions contestable. But 
in the biological account, the definition of death captures just one very straightforward, universally applicable idea - irreversible loss of organismic functioning - which is suspiciously simple. Conversely, consider concepts that are non-contentiously purely biological, such as the concepts of photosynthesis and osmosis; is it really plausible that the concept of death is, like these, purely biological? (Holland, 2010, p. 112)

For the purposes of this chapter we are most interested in the observation by Holland that 'whilst our ordinary understanding [of death] accommodates the biological definition, it also includes the thought that, for someone who has died, there will never again be anything it is like to be that person' (Holland, 2010, p. 109).

It comes as no surprise, then, that family members often rearticulate and negotiate the notion of 'consciousness', which functions as a key signifier in dominant biological and medical definitions of death. Indeed, the situation is complicated by whether or not family members really believe that consciousness is entirely absent even in the patient's present condition. Vegetative patients do not conform to the image of the 'coma patient' so often displayed in the media - they often do not appear to be unconscious in our usual understanding of what unconsciousness 'looks like'. Vegetative patients usually have spontaneous respiration and circulation (they are not dependent on machines to breathe or to keep their hearts beating) and they have sleep-wake cycles and while awake can open their eyes and may look toward a loud sound or stare at a visitor (medically called 'visual fixation'). They also may withdraw from pain, cry, smile, groan and have a grasp reflex (which a visitor may experience as hand holding). Such patients may sometimes even say isolated words which, according to clinical experts, may reflect 'the survival of "islands" of cortex, which are no longer part of the coherent thalmo-cortical system required to generate awareness' (RCP, 2013, p. 5). Families, however, may see such behaviours as evidence of awareness and question clinical definitions. (For discussion of contestations around the diagnosis of consciousness see Nettleton et al., forthcoming.) This is further complicated by recent findings from scientists using new techniques of brain scanning that appear to detect brain activity in patients apparently unable to display any other signs (for example unable to blink answers to questions) (see Monti et al., 2010, and disputes about the representation of fMRI, e.g. Samuel and Kitzinger, 2013; Turner-Stokes et al., 2012). Families may believe the person 'is in there' and responding to them, and question the ability of experts at the bedside to detect this. 
In addition it is widely recognised (by both clinicians and families) that patients can be misdiagnosed as VS when in fact they are MCS (Andrews et al., 1996) and families often fear the patient may even be 'locked-in' - fully conscious but unable to communicate in any way and there have been some examples of misdiagnosis in such cases too (although this is much less likely). Distinguishing VS from MCS is particularly challenging because, by its very definition, MCS is characterised by inconsistency and MCS is also a continuum (for example some patients display very, very minimal and very, very intermittent signs of consciousness). The creation of the VS/MCS boundary therefore, on one level, seeks to clarify the situation, but at the same time creates 'a mirage of certainty' - a 'diagnostic illusory' - which 'does little to quell the confusions, anxieties, conundrums and conflicts experienced by relatives, and some clinicians' (Nettleton et al., forthcoming, p. 16).

Families' understandings of their relative in a vegetative state are not only connected to - often contestations of - biomedical definitions of death and dying, but are also embedded in debates that go beyond the medical and biological sphere. The 'permanent vegetative state' has indeed a special significance and is often used as a 'thought anchor' in philosophical as well as theological theorising about life, death, and personhood. Analysing the ontological status of the patient in PVS (with irreversible, permanent loss of awareness of themselves or their environment) is a useful endeavour for thinking through the philosophical implications for treatment (Holland et al., 2014). However, as we will show in this chapter, on another level this approach has limited use for families facing the day-to-day challenges of having a loved one in a disordered state of consciousness - trying to make sense of their own feelings and experience, and encounters with current legislation and practice as these play out over time and as the patient moves across different diagnostic categories. This is because in many theoretical accounts PVS is presented in a static way and imagined as an abstract ideal, without an engagement with the medico-legal context in which such states are created/emerge over the patient's 'pathway' and disconnected from other states of disordered consciousness or what decisions have to be made or what 'recovery' can mean. One key issue is that the diagnosis of a disorder of consciousness is a process, not a one-off event the diagnosis of such a state as being 'permanent' is time dependent and embedded in debates about when someone in a vegetative state can be defined as having 'irreversibly' lost all capacity for consciousness (should it be after months, a year, or years?) and what interventions and tests should be tried (might another drug trial make a difference?). Guidelines 
vary between countries. For example, in the US you can be defined as being in a 'permanent' vegetative state after showing no consciousness for three months after a 'non traumatic injury' (for example due to oxygen deprivation), whereas in the UK that label can only be applied after six months (RCP, 2013). In both countries patients can only be labelled as PVS after a year if the cause of their injury is 'traumatic' (such as due to a blow to the head). There are a few isolated examples of late recovery from PVS and it is known that people may sometimes evolve into full consciousness, after years or even decades in MCS (Fins et al., 2007). Family members' sense of the person as 'alive' or 'dead' will, in part, play out against this understanding of when loss of consciousness is 'irreversible' - both according to the medics (depending on the country in which they live) and their own understanding of the treatment given and what the future holds.

\section{Method}

The research reported here is part of a larger ongoing study of family experiences of decision making in connection with a severely brain-injured relative. We have also interviewed professionals in the field. Ethical approval was obtained from University of York and Cardiff University ethics committees and all interviews were conducted by one or other of the authors of this paper (both experienced in interviewing around highly sensitive subjects). Family research participants were recruited through advertising via support groups, websites and care homes asking people to talk to us about the experiences of decision making. We also recruited through our own social contacts (we have a severely braininjured sister), ${ }^{1}$ through contacts made after giving formal presentations about our research and via snowball sampling. Once we received NHS ethics approval (from Berkshire Research Ethics Committee, REC reference number: 12/SC/0495) we were also able to recruit via consultants, although all interviews took place off NHS premises (generally in people's homes).

We interviewed a wide range of family members: adult children, parents, sisters, brothers, spouses and partners of the brain-injured person, as well as some other relatives involved in decision making (for example stepfather and sister-in-law). Most people were interviewed individually, but some asked to meet in pairs (for example a husband and wife asked to be interviewed together, as did a mother and daughter). We almost always conducted the interviews without other people present: exceptions were one interview at which a young child was present and 
another which took place in the same room as the PVS daughter of the interviewee (who cared for her at home).

The interview schedule was deliberately wide-ranging, with openended questions, prompts and follow-up questions employed to elicit detailed responses but also to allow people to tell their own stories, rather than adhering to a strict structure. The majority of interviews lasted between 2 and 4 hours (with breaks). In this article we focus on those parts of the interviews where participants implicitly or explicitly reflect on their relatives status as alive or dead.

We have interviewed 51 family members - their injured family member ranged from late teens to early sixties. Most of the brain injuries were caused by either road traffic or sporting accidents and most were traumatic rather than anoxic (oxygen deprivation) injuries. At the time of interview, the brain-injured persons had generally been kept alive for between two and ten years since the injury, and most had been diagnosed as 'vegetative' or 'minimally conscious' (although some had died, and some had recovered full consciousness, albeit with profound and multiple disabilities).

In addition, one interviewee reported the experience of having his daughter diagnosed as 'brain dead' and 'switched off', and another interviewed because she had a relative who was vegetative - also reported an experience of the brain death of another family member.

Interviews were fully transcribed and, following discussion between the researchers, coded to identify themes and recurrent issues using a qualitative analysis software package (Dedoose). Issues pertaining to death which were attended to included: descriptions of 'near death' or the patient having 'died' and been 'reanimated' (for example through resuscitation), explicit or implicit accounts of the relationship between the patient's current existence and death, expressed views about life-sustaining treatment and future death, and discussion of actual or planned funeral rituals. The authors analysed the data using thematic analysis to identify patterns (themes) within data (Braun and Clarke, 2006) and paid particular attention to diversity within the data and the ways in which people spoke about the relationship between the body and the soul/spirit/person and the terms they used to express ideas about life and death, ('existence', 'breathing', 'being' or 'free', 'at peace', 'passed over', 'gone'). The data are replete with tensions, speculation and ambivalences that are perhaps inevitable given the ways in which vegetative (and minimally conscious) states may disrupt standard constructions of life and death and the emotional complexity of family responses. In the data discussed in the analysis here we have tried to capture some of 
these tensions, and to highlight both the commonalities and the diversity of responses as our interviewees grapple with the challenges they confront.

In the analysis which follows we describe the reported experiences of the families who talked to us, on their own terms, contextualising these in relation to the medical, legal and ethical situations which they reflect and constitute. All data have been anonymised. Names of people and places are pseudonyms. (For full discussion on anonymising strategy see Saunders et al., 2014.)

\section{Findings}

This chapter explores questions such as: when is someone 'dead' or 'alive'? If someone has not died - why not? Should they be dead? What do such states of 'in-between' mean for relationships? What would it mean if they really did die - in terms of memory and commemoration?

\section{When is someone 'really dead'?}

Two of our interviewees not only had experience of vegetative/minimally conscious states, but also had experienced a relative with a diagnosis of brain death - and during the interview they talked about the death of these relatives. Both described their somatically-maintained brain-dead relative as having been in some sense present, at least as a subject for 'being with' and saying goodbye to, even while accepting the diagnosis. One, for example, described how her husband got to be 'actually dead' only after his 'life support' was switched off and describes how important it was to be with him while he 'died'.

Inga: I said, 'oh yes, I want to be in there', the girls said they wanted to be. So they just removed the ventilator and he just lay there. And you could see - he was still attached to the monitor and you could see - I mean, I never realised it would take so long for somebody to actually die in that situation.

Int: How long did it take?

Inga: Well, I just thought it'll - his heart will stop, you know. And the thing was, it started slowing down and we were all holding him and everything. And then it sort of stopped and it flat lined. And you know we thought, 'Oh God, that's it'. And then it started again. And it kept doing this. So we didn't know, we kept thinking, 'Oh, is he or isn't he?' Oh, it was awful, it was absolutely horrible. It felt like it was about ten minutes. It was 
probably maybe half that. But it was just horrendous, absolutely horrendous. Sorry, I'm reliving it (tearful).

Int: I can understand that. Did you wish you hadn't been there?

Inga: No, no. We had to be there. You know I couldn't have left him then.

Keith similarly talks about the rituals of saying goodbye to his braindead daughter. He says she was 'dead' - 'as far as they [the doctors] were concerned', but it is clear that for him she was not 'gone' until after the machines were switched off.

Keith: It was global [brain injuries] in the end. It got worse and worse. It sort of spread, the swelling became bigger [...] She was clinically dead once immediately the machine went off.

Int: The machine being the ventilator?

Keith: Yes [...] We were told that it was hopeless, and it was their opinion that the minute that they turned the vent off that she would die. In fact she was dead as far as they were concerned without the machine. So people just filed in, [...] to say their goodbyes and that was awful. [...] And very soon she was almost gone instantly there was just nothing there when they did it.

These extracts confirm what previous research has demonstrated (Lock, 2002) - that 'brain death' is often not actually treated by relatives as 'really dead'. In these scenarios the already brain-dead are 'actually dying' (and take 5-10 mins to do it) or are only 'gone' after the ventilator is turned off. The recent Jahi McMath case offers a particularly graphic case of a family's refusal to accept that a brain-dead patient is really 'dead' - and some media reports explicitly related this case to those of PVS/MCS patients (for example http://content.time.com/time/magazine/article/0,9171,2162277-1,00.html). Although recognising that the medics spoke of the person as 'already dead' what our interviewees treat as (real) death is cardiovascular death (as signalled by the flat-lining of the monitor). This is a firmly biological rather than consciousness-based definition of death - even though this wife and this father accept that consciousness has gone (that is, the person is brain dead) and even (at an intellectual level) that this means the person is 'dead', there is still something very compelling about being with a body that is warm and breathing (albeit with a ventilator) which leads us to experience it as 'alive'. But, these interviewees had only a few days of experiencing a body 
without consciousness. In the rest of our analysis we address how families experience being with relatives who have no (or minimal) consciousness long term. As with 'brain dead' patients, the vegetative and minimally conscious patients started off in intensive care - but, unlike them, they have survived independently of ventilators: they are not 'gone' (that is 'brain dead') and there has been no final 'goodbye'. How then do interviewees talk about life and death in relation to these patients?

The way in which interviewees explicitly tried to present their relative as living or dead to some extent mapped onto their views about the meaning of life. For some interviewees life, at all cost, was to be valued and should not be discriminated against. Life without consciousness was still life (or at least retained the possibility of recovery for future life). For others, however, the disordered state of consciousness fundamentally compromised the meaning and quality of life. Families whose relatives had clear PVS diagnoses (especially those who were seeking the discontinuation of life-sustaining treatment) often made the strongest statements about their relative being at least 'not alive': 'she's existing, she isn't living' (Natalie); 'she died four years ago' (Harry); 'It's Colin's body being kept alive somehow. He's not in it anymore' (Jade); 'He's already dead' (Brian). (For further discussion see Holland et al., 2014.) For them the continued artificial maintenance of the body was unnatural or perverse. However, even some relatives who were in favour of ongoing life sustaining treatment sometimes revealed a different perspective through 'slips of the tongue' while talking to us. Kathy, for example, had strong spiritual beliefs that her sister's current state of suspension was 'for a reason' but said of her sister: 'if Bella were alive - oh! Say again! If Bella were awake, conscious...'

Family members who felt their loved one would be 'better off dead' also sometimes emphasised that their relative was actually very much alive - with present experience and sensations. It was unusual for family members to view their relative as 'comfortable' - twitching, grimacing, and teeth grinding can make the vegetative body/person appear distressed. Seizures may also occur. And minimally conscious patients are known to experience pain. Indeed interviewees with an MCS relative sometimes looked back on a time when their relative showed no awareness at all with something like nostalgia: 'It was better when he was vegetative', comments one, 'there was just emptiness'.

Perceived suffering was part of the rationale some relatives had for speaking of their relative as very much alive and contrasting this explicitly with being dead - a state for which they used terms such as 'at 
peace'. (For further discussion see Kitzinger and Kitzinger, 2014.) One interviewee, for example, while accepting the experts' PVS diagnosis for her relative was adamant about the horrendous nature of his life:

If you start mucking around with the brain you can be left with what did happen, and that is worse than death you know. [...] People don't want to believe that people are living such horrendous lives. They go 'oh I'm sure there's something'. Well no there isn't always something. Life isn't always better than death. And it shouldn't be life at all costs. (Rose)

This interviewee, in this context repeatedly uses the words 'living', and 'life' - emphasising the horror of continued existence in such a state. She went on to argue that active euthanasia should be available in such circumstances.

\section{What caused someone to still be alive?}

All of these families' relatives would have died without medical intervention and interviewees whose relatives had been resuscitated often talked about their relative as having 'actually died'- but death having been 'arrested' or 'reversed'. Frieda says her mother, injured in a riding accident: 'kept on dying' but a doctor at the scene kept reviving her until the ambulance arrived and that 'she died several times' in the ambulance 'but they kept her going'. Ann says her daughter drowned and 'did really die' at the site where she was found. Felicity says her partner, who collapsed with a brain infection: 'actually did die, once for six minutes and once for eight'.

The way these interviewees talk about their relatives (near) death is inflected through their perception of their loved one's present state or potential future condition. When Ann, for example, declared that her daughter (who remains in a vegetative state after many years) 'really did die' at the accident site, her other daughter (in an interview with the two women jointly) added 'we do find it stupid that they didn't leave it at that'. By contrast Felicity, who (against all medical advice) passionately maintains a belief in her partner's future recovery, talks as if she imagines regaling him with the tale and speculates about the impact of having died on his future appreciation of life:

He has died twice, (laughs) do you know what I mean [...] And I can't see how he would not have different appreciation for life now. Especially when he realises that 'you died, do you know, you died 
twice, and you nearly died every day for months and months and months' $[\ldots]$ me and a friend of his always joke that we're going to ask Nin if he saw the light. 'What did you see, Nin? What did you see?'

The meaning of such closeness to, or return from, death is also presented in different ways depending on interviewees' attitude toward the past, present and future. Some of the interviewees thereby construct the 'natural death' in negative relation to the 'artificial life'. One mother, for example, talked angrily about the medical system that had intervened to prolong her daughter's life against the wishes of the family (and, she believes, her daughter's own wishes). She described her daughter's current existence as a kind of 'artificial life', created by doctors who have no respect for who her daughter had been and no knowledge of the family's culture: 'we're acting as if these are people from outer space and we can somehow keep them going and it's very clever of us'. A similar perspective was presented by another interviewee who described how medics operated to save her mother's life against the wishes of the family. This interviewee reflects bitterly on the fact that by the time clinicians did eventually decide to turn off her mother's life support it was too late - the crisis was over and the body's instinct for survival ensured her mother kept breathing:

It seems sort of bitter and ironic that, $[\ldots]$ they'd given her $[\ldots]$ just enough time for her to gather just enough strength to muster up a hold. [...] they'd intervened massively once and then, just as significantly, a second time [with operations]. And she didn't die when they turned off life support. Off she went - breathe, breathe.

By contrast other interviewees interpreted the continued existence of their relative against all predictions as a sign that the patient had a positive motivation to survive and would defy the grim statistics about the severe impairments they were likely to face if they ever did recover consciousness. Stavos, who, like Felicity, apparently anticipates a time when he will be able to communicate with his brother, sees his survival as evidence of his brother's determination to live and looks forward to helping his brother write a book about his experience. Other families do not imagine such high-level recovery, but still see ongoing survival as indication of a higher spiritual purpose, or the hand of God. Kathy, for example, thinks her sister still has a 'purpose' in life, if not for herself then for others, and Felicity reacts to the fact her husband survived two prolonged cardiac arrests, by declaring: 'If that man was meant to die, 
I believe God would have took him then [during the cardiac arrests]. That's my faith.' Felicity's account recalls confrontational encounters with doctors reluctant to keep treating him and describes the impression she was left with after one such meeting with a consultant who wanted to switch off her husband's ventilator:

I said, 'you can't do that, do you know, he's a man, he's my partner, I've got a baby, he's my baby's dad' [...] And he [the consultant] started saying to us [...] 'I will not keep a slab of meat, that's all he will be, a slab of meat alive in my room, I won't do that, that's undignified [...] he will just be dead but in the body' - do you know, I can't remember the words now, it was just he had no compassion for us. He was just getting his point across.

Months later another consultant questioned Felicity's insistence on aggressive intervention (Nin's weight had dropped to under six and a half stone and he was having regular seizures) and Felicity successfully argued for treatment again:

I guess some people feel $[\ldots]$ that people are trying to die and you're not letting them [...] But I hope that I have the right judgement to make that decision, if I felt that Nin was ready to go, that he'd had enough [...] But then again, I'd probably leave it up to God because when Nin's time to go is to go, I don't think it matters what equipment I would use.

\section{Relationships, 'social death' and 'life'}

Definitions of death have been well-researched in the context of defining 'brain death' for the purposes of organ harvesting (Lock, 2002). However, another reason why it matters whether a person is 'dead' or 'alive' is because of the implications for relationships. (See, for example, Behuniak, 2011, on 'social death'.) The picture that emerged from our interviews was complex and somewhat double-edged. Some of these relatives declared their loved one 'gone'. A husband, for example, said of his wife 'to all extent and purposes, she no longer exists' and a mother said of her son 'his body's just going to outlive him... It's like a bereavement but you can't grieve and they [care staff] keep telling me he's not

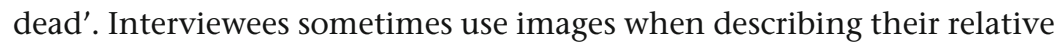
that are alien, inanimate or animalistic (for example 'zombie', 'husk', 'dummy' - for a critique of such language see Behuniak, 2011). This 
could lead for them to fight for 'death with dignity' - a desire to bury the body that was outliving the person. On the other hand some (sometimes the same people) emphasised that their relative was very much still alive, and use this to assert the patient's claim to social acknowledgment and respectful and interactive care. Tania reacts angrily to friends and acquaintances who have stopped asking about his son declaring 'he's still alive'. Morag makes a similar assertion in her message to staff:

Don't talk over him like he's a piece of meat or like he's not even there; or like he's already dead because he's not.... he's a living, breathing human being.

Although everyone wanted the person/body treated with care and respect for some interviewees the 'death' (or at least absence of personhood) meant there was no reason to visit, that energy should be focused on 'the living' (such as their children), or that visits were simply out of duty and involved 'going through the motions'. Individuals were often ambivalent and families occasionally split around such decisions - for example a mother might continue to visit, but a husband declare there was no point, or one family member may wish 'life-sustaining' treatment to continue, the other to allow death. Some were critical of other relatives and the role they had adopted in relation to the patient. One, for example, reflects negatively on the way her son's grandmother has moved in on her son's life - 'it is as if she owns him'; another describes a mother's (in his view misguided) devotion to maintaining her son's life and visiting him every day:

It was the mother that insisted that he [her son in a vegetative state] was going to get considerably better and also that she was communicating with him, she knew what he wanted, she knew what he was saying, and then she died, [...] what sort of sick joke is that. You know she's killed herself trying to keep him alive and he's dead anyway.

Some interviewees were also self-critical about quite what they were devoted to. One woman said she thought she was keeping her husband alive 'for me', rather than for his own sake. A mother, caring for her vegetative daughter at home reflects that it is a bit like keeping a human being 'as a pet':

What we're doing could be seen as a selfish act [keeping our loved one alive]. Because we don't want to lose them. We want to keep them here with us. But all you're keeping is a shell. 
However, some interviewees felt there was still some point to their relative's life - some connection either through subtle communication such as eye opening or through their ongoing social roles with or without active participation ('he's my partner....he's my baby's $\left.\mathrm{dad}^{\prime}\right)$. Morag, for example, appreciated the many years in which her father had survived in a vegetative (or probably minimally conscious) state:

To have had him there, at least, you know, we could tell him about our GCSEs [school examinations at 16 years old], we could tell him about our A Levels [examinations at 18 years old]. And I remember my cousin got married and we were bridesmaids and we went between the church and the reception, we went to the hospital and we left our bouquets in the hospital and had photos taken with him. You know, so he was still part of what was going on.

Morag emphases the ongoing social relationship with her father through her own growing up and is grateful he was still part of their lives, although she added 'but on the other hand, our lives stopped for nearly a decade, particularly my mum's'. However, two women involved in our research actually saw their lives as in some ways improved by their partner being in a disordered state of consciousness. One saw her partner being in a coma as 'easier than breaking up' and found visiting 'peaceful' and 'connected'. Another also talked of the pleasure she took in visiting her husband and described the dramatic change in their relationship once he was in a vegetative (or possibly minimally conscious) state. Through fighting for him to continue to receive treatment, she had found her own power and voice within a relationship in which she had previously been very disempowered and controlled by him (Saunders et al., in press). In both cases these women wanted life-sustaining treatment to continue in spite of opposition from other family members and/or clinicians.

\section{The spirit and the soul - memory, funerals and resolution}

Whether or not they were religious many interviewees evoked a concept of 'spirit' or soul. Some made comments about medical science 'trapping' the soul in the body artificially, others saw 'the soul' as making a choice to stay - and ideas about spirituality and the meaning of life were mobilised in thinking about death. One mother commented that allowing her daughter to die would be a positive move, better than keeping her trapped in her body: 
Do you know in a way, it sounds too goofily spiritual perhaps, but I don't believe death is the end - we have an effect on life, the future, other people's lives beyond our own death, or can have. So I don't think it's like a door slamming.

Memory of the person who had 'gone' was often crucial to interviewees' judgment. Interviewees talked of wanting to remember their loved one as they had been ('vibrant', 'alive') and emphasised the importance of how their relatives themselves would want to be remembered.

Fantasies about funerals were often linked with closure, memory and commemoration. ${ }^{2}$ Ann, whose daughter has been in a vegetative state for many years, recalled how at the beginning: 'I thought it would be nice to have a month to say goodbye' but when she was told her daughter might survive for years:

I was very aware at the time that I wanted to remember Fiona as she was. I didn't want it to drag on for months and I didn't want my memory of Fiona to be these months and months of suffering.

Ann's other daughter, Bea (in a joint interview), explained how she planned the funeral, going through all her sister's favourite CDs to choose music for the event. She contrasts being able to choose music with the difficulty of choosing 'least worst' options in relation to medical treatment.

I was really pleased that I'd had the chance to do that. She'd be really pleased with the decisions made for her funeral [...] Planning a really nice do, and choosing the music was a decision on something that I could be proud of planning for her.

Other families also talked at length about the funerals that they had planned, but never been able to have. Diane, whose mother had been injured when Diane was still a teenager, commented:

I fantasize about $[. .$.$] her funeral basically - being able to be united$ and to celebrate her and you know remember her in a sort've... not in this [...] this blackness that lives with you, that sort of plunging despair that lives inside you [...] It would've been a tragedy that Mum had died $[\ldots]$... but it would've been ... we would've been able to go forward. As it is we're stuck, all of us, behind this glass wall and when she dies ... although it's been so long, you kind of imagine it's all going to be okay when she dies. 
Diane's older sister, in a separate interview, also talked of thinking about her mother's funeral.

I go through phases of dreaming about Mum's funeral but dreaming about talking to her as she's dying about, talking to her in her coffin endlessly, [... There's a lot of, kind of, turmoil around the idea of her dead and not dead, dead and not dead, here and not here. You know it's the, the sort of, it's just the unresolved...

\section{Conclusion}

This chapter has highlighted ordinary understandings of death as they are mobilised in extraordinary circumstances by families of severely brain-injured individuals. The analysis underlines that death, as also other chapters of this volume make clear, is not a fixed category - and death and dying derive their meanings through contingent signifying relations. New technologies, and ways of deploying those technologies, have created new forms of liminal beings who occupy an ambiguous position ('dead and not dead, here and not here') and our interviews with family members highlight the work done by family members as they try to deal with, and make sense of, the challenges this throws up for them in the context of their own experiences, cultures, religious and spiritual beliefs, knowledge of their relative's values, their own relationships and wishes, and their engagement with the legal-medical system.

Family members negotiate different constructions of life - the biological (the still warm body and beating heart), the consciousness based paradigm (focused on the patient's awareness) and relational elements (the place of the person in the family). Such negotiations take place against a background of uncertainty and shifts over time (because the 'permanence' of the disordered state of consciousness is only confirmed after months or even years) and sometimes very confusing experiences at the bedside (when the patient may display behaviours that raise questions about their level of awareness). Any simple reclassification of the being as 'dead' is complicated by the warm, breathing body, the organisation of care around sustaining 'life' (often in the apparently 'domestic' and nonmedicalised setting of a long-term 'care home' or 'rehabilitation centre'), and the social space occupied by the individual (as husband, son, sister or partner). It is also complicated by the uncertainty families may experience about when, and if, the state has become permanent, and whether their relative might just have some minimal consciousness - as well as the values they themselves place on different meanings of life. 
It is not surprising that our data show that families explicitly negotiate, and struggle, with these challenges. They take explicit positions about whether their loved one is dead or alive, but then stumble over words in trying to make sense of the situation - sometimes referring to their relative as dead, but correcting themselves, or speaking about the patient as both living and dead in the same sentence. It is also not surprising that different ways of looking at the body/person can be a source of conflict sometimes between families and friends, but more Often, in our data, between families and professionals. This was evident, for example, for the mother who feels doctors have created 'artificial life' in sustaining her daughter, and the other who says that staff 'keep telling me he's not dead'. The same conflict is apparent in the words of the daughter who admonished staff: 'he's [not] a piece of meat.... he's a living, breathing human being', and in the report of the wife who describes her horror at the intensivist who dismissed her husband as 'dead but in the body' and wanted to treat him as simply 'a slab of meat'.

This chapter illustrates that social constructionist/ivist approaches to death are not limited to the ivory towers of academia, but, for these families, become an integral part of trying to make sense of the experiences and systems they confront under the most traumatic of circumstances. Close attention to such accounts will help round out social constructionist/ivist accounts, place abstract theorising about the 'PVS' category in context and may suggest how understandings of discourses around death may help families and clinicians, and assist in framing policy and practice - including the delivery of so-called 'life-sustaining' treatment.

\section{Acknowledgements:}

This paper was part-funded by the ESRC (Ref: ES/K00560X/I) and by Research Priming Funds provided by the Wellcome Trust [ref: 097829/ Z/11/A] through the Centre for Chronic Diseases and Disorders (C2D2) at the University of York.

\section{Notes}

1. For discussion of the challenges and opportunities of 'insider research' see Saunders et al. (under submission).

2. The importance of ritual in the marking of death has been explored in many studies, and the liminal has been theorised. For example, in some societies, the dead may not be quite dead until their bones have been exhumed or collected and then burned, cleaned and buried in another place from the first 
internment. Therefore, between the biological death and the final recognition that the spirit has joined the spirit world, the ghost of the dead may walk the earth for a while. This is a liminal, in-between, transitional state (Kellehear, 2007).

\section{References}

Abdennour, L., Lescot, T., Weiss, N., Galanaud, D., Naccache, L., Carpentier, A. and Puybasset, L. (2007). 'On the difficulty of traumatic brain injured patients' end of life decisions', Annales Françaises d'Anesthésie et de Réanimation, 26(5), $445-451$.

Andrews, K., Murphy L., Munday, R. and Littlewood C. (1996). 'Misdiagnosis of the vegetative state: retrospective study in a rehabilitation unit', British Medical Journal, 313, 13-16.

Aries, P. (1981). The hour of our death. New York: Alfred A. Knopf.

Bird-David, N. and Israeli, T. (2010). 'A moment dead, a moment alive: how situational personhood reasserts itself in the vegetative state in an Israeli hospital', American Anthropologist, 112(1), 54-65.

Behuniak, S. (2011). 'The living dead? The construction of people with Alzheimer's disease as zombies', Aging and Society, 31(1), 70-93.

Braun, V. and Clarke, V. (2006). 'Using thematic analysis in psychology', Qualitative Research in Psychology, 3(2), 77-101.

Carpentier, N. and Van Brussel, L. (2012). 'On the contingency of death: a discourse-theoretical perspective on the construction of death', Critical Discourse Studies, 9(2), 99-115.

Carter, B. S. and Leuthner, S. R. (2003). 'The ethics of withholding/withdrawing nutrition in the newborn', Seminars in Perinatology, 227(6), 480-487.

Cranford, R. (2002). 'What is a minimally conscious state?', Western Journal of Medicine, 176(2), 129-130.

Fins, J., Schiff, N. D. and Foley, K. M. (2007). 'Late recovery from the minimally conscious state: ethical and policy implications', Neurology, 68(4), 304-307.

Giacino, J. T., Ashwal, S., Childs, N., Cranford, R., Jennett, B. and Katz, D. I. (2002). 'The minimally conscious state: definition and diagnostic criteria', Neurology, 58(3), 349-353.

Giacomini, M. (1997). 'A change of heart and a change of mind? Technology and the redefinition of death in 1968', Social Science and Medicine, 44(10), $1465-1482$.

Gillett, G. R., Honeybul, S., Ho, K. M. and Lind, C. R. P. (2010). 'Neurotrauma and the RUB: where tragedy meets ethics and science', Journal of Medical Ethics, 36(12), 727-730.

Holland, S. (2010). 'On the ordinary concept of death', Journal of Applied Philosophy, 27(2), 109-122.

Holland, S., Kitzinger, C. and Kitzinger, J. (2014). 'Death, treatment decisions and the permanent vegetative state', Medicine, Health Care and Philosophy, 10.1007/ s11019-013-9540-y http://link.springer.com/article/10.1007/s11019-013-9540-y

Honeybul, S., Ho, K. M., Lind, C. R. P. and Gillett, G. R. (2011). 'Surgical intervention for severe head injury: ethical considerations when performing life-saving but non-restorative surgery', Acta Neurochirurgica, 153(5), 1105-1110. 
Illich, I. (1975). Medical nemesis. London: Calder and Boyars.

Jennett, B. and Plum, F. (1972). 'Persistent vegetative state after brain damage: a syndrome in search of a name', The Lancet, 1(7753), 734-737.

Kaufman, S. (2003). 'Hidden places, uncommon persons', Social Science and Medicine, 56(11), 2249-2261.

Kaufman, S. and Morgan, L. (2005). 'The anthropology of the beginnings and ends of life', Annual Review of Anthropology, 34(XX), 317-341.

Kellehear, A. (2007). A social history of dying. Cambridge: Cambridge University Press.

Kitzinger, C. and Kitzinger, J. (2013). "The "window of opportunity" for death after serious brain injury: family experiences', Sociology of Health and Illness, 35(7), 1095-1112.

Kitzinger, C. and Kitzinger, J. (2014). 'Withdrawing artificial nutrition and hydration from minimally conscious and vegetative patients: family perspectives', Journal of Medical Ethics, DOI:10.1136/medethics-2013-101799.

Lock, M. (2002). Twice dead: organ transplants and the reinvention of death. Berkeley: University of California Press.

Monti, M. M., Vanhaudenhuyse, A., Coleman, M. R., Boly, M., Pickard, J. D., Tshibanda, L., Owen, A. M. and Laureys, S. (2010). 'Willful modulation of brain activity in disorders of consciousness', New England Journal of Medicine, 362(7), 579-589.

Nettleton, S., Kitzinger, J. and Kitzinger, C. (forthcoming). 'A diagnostic illusory? The case of distinguishing between 'vegetative' and 'minimally conscious' states', Social Science and Medicine.

RCP [Royal College of Physicians] (2013). Prolonged Disorders of Consciousness. National clinical guidelines. London: RCP.

Samuel, G. and Kitzinger, J. (2013). 'Reporting consciousness in coma: media framing of neuro-scientific research, hope, and the responses of families of vegetative and minimally conscious patients', JOMEC Journal, 3, 1-15.

Saunders, B., Kitzinger, J. and Kitzinger, C. (submitted). 'Anonymising interview data: Challenges and compromise in practice', Qualitative Research.

Schaller, C. and Kessler, M. (2006). 'On the difficulty of neurosurgical end of life decisions', Journal of Medical Ethics, 32, 65-69.

Turner-Stokes, L., Kitzinger, J., Gill-Thwaites, H., Playford, D. E., Wade, D., Allanson, J. and Pickard, J. (2012). 'fMRI for vegetative and minimally conscious states [Editorial]', BMJ 345 (nov28), doi: 10.1136/bmj.e8045

Wilkinson, D. and Savulescu, J. (2011). 'Knowing when to stop: futility in the ICU', Current Opinion in Anesthesiology, 24(2), 160-165.

Youngner, S. J. H., Arnold, R. M. and Schapiro, R. (1999). The definition of death: contemporary controversies. Baltimore: John Hopkins University Press.

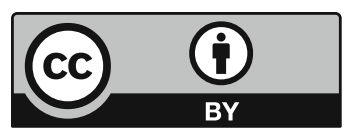

Except where otherwise noted, this chapter is licensed under a Creative Commons Attribution 3.0 Unported License. To view a copy of this license, visit http:// creativecommons.org/licenses/by/3.0/ 